\title{
Otomatik Armonizasyon İşlemli Müzik Yazılım Programları Üzerinde Çokseslendirme Analizleri
}

\author{
Polyphonic Analyses On Automated Armonisation Processing Music \\ Software
}

$\mathrm{DOI}=\underline{10.17556 / \mathrm{jef} .04612}$

Ali Korkut ULUDAĞ

Özet

$\mathrm{Bu}$ araștırmanın temel amacı, Tonica Fugata, Sibelius ve Finale adlı müzik yazılım programları içerisinde yer alan otomatik armonizasyon özelliklerinin geleneksel klasik armoni kuramının temel ilkeleri ile örtüşen ve ayrışan yönlerini tespit etmektir. $\mathrm{Bu}$ tespitler, araştırmacı tarafından hazırlanmış çokseslendirme örnekleri ve programların otomatik armonizasyon işlemlerindeki sonuçlarının analizleriyle ortaya konulmuştur. Araştırma içerisinde daha kapsamlı analizler elde edebilmek için programların orkestrasyon düzenleme şekilleri ve akor tanımlama özellikleri de incelenmiştir. Özellikle Tonica Fugata programı içerisinde yer alan iki farklı J. Sebastian Bach ekolü, Samuel Scheidt ve Teststil gibi farklı armonizasyon stillerinden elde edilen armonizasyon işlemlerine yönelik sistematik bir puanlama gerçekleştirilmiştir. Araştırmacı tarafından uzman görüşleri doğrultusunda hazırlanan dereceli puanlama anahtarı içerisinde her bir ölçünün birbirinden bağımsız olarak değerlendirilmesi yapılmıştır. Elde edilen veriler, J. Sebastian Bach II armonizasyon işlemi ve geleneksel klasik armoni ilkeleri arasında daha benzer sonuçların ortaya çıktığını göstermiştir.

Anahtar Sözcükler: Armoni, müzik yazılım programları, analiz, çokseslilik

\begin{abstract}
Main objective of the present study is to determine the overlapping and contrasting ways of automated armonisation characteristics which some music software programs shelter, like Tonica Fugata, Sibelius and Finale with basic principles of traditional classical armony theory. Researchers put forward the results through polyphonic samples prepared before and the analyses of findings obtained in the armonisation processes. In order to obtain more comprehensive analyses in the study, orchestration design types and accord definition characteristics were also evaluated. A systematical scoring was performed towards armonisation processes obtained from different armonisation styles like J. Sebastian Bach ekolü, Samuel Scheidt ve Teststil in especially Tonica Fugata program. Graded scoring key prepared by the researcher considering expert views allowed to evaluate independently each scale. Dataset obtained showed that there are more similar
\end{abstract}


results between J. Sebastian Bach II armonisation process and traditional classical armony principles.

Keywords: Armony, music software, analysis, polyphony

\section{Giriş}

İnsanlığın var olduğu günden beri sürekli gelişim gösteren teknoloji, geçmişi içinde barındıran yapısıyla birlikte son yüzyılda daha fazla yol katetmiştir. Bu gelişmelerin etkisiyle birlikte teknolojik bir niteliğe ulaşan günümüz insanı eğitimde önemli değişimlere yol açmıştır. Diğer bir ifadeyle, yeni koşullar karşısında biçimlenen eğitim ve teknoloji arasında insan kaynaklı ilişkilerden söz etmek mümkündür. $\mathrm{Bu}$ gelişim aşamalarının müzik bilimi alanlarına yansıması ise kaçınılmaz olmuştur. Azizi (2005) son yüzyılda teknolojinin eğitimin her alanında olduğu gibi, müzik eğitimi alanında da yaygın olarak kullanıldığını ve müzik eğitimine değişik bir bakış açısı kazandırdığını belirtmektedir.

Bilgisayar destekli müzik yazılımlarının genel özelliklerine bakıldığında; programları çeşitli gruplara ayırmak mümkündür. Müzik eğitim programları (Instructional Software), pratiğe ve uygulamalara dayalı yazılımlar (Practice/Accompaniment Software), nota yazım programları (Notation/Scoring Software) ve bir çeşit devinim oluşturarak müzik yapmaya yarayan masaüstü 'Sequencer' sistemleri (Sequencing Software), önemli alan başlıklarıdır (Koç, 2004). Bütün bu programların ve online sistemlerin müzik eğitiminde etkin olarak kullanılması, öğretim sistemini tamamlayıcı ve güçlendirici bir unsur olarak öğrencilerin öğrenme süreçlerini hızlandıracak, gelişmek istedikleri alanda zengin bir materyale sahip olmalarına neden olacaktır (Levendoğlu, 2004). Bu açıklamalar Arapgirlioğlu (2003)'nun “Türk Okul Şarkılarının Teknoloji Destekli Çokseslendirilmesine İlişkin Yaklaşımlar" başlıklı çalışmasından çıkarılan şu sonuç ile desteklenmektedir: Teknoloji desteği ile çokseslendirilen okul şarkılarının çocukların ilgi ve beğenisini daha fazla çektiği, defalarca bu şarkıları tekrar etmekten zevk aldıkları tespit edilmiştir (Sevinç, 2003).

Bilgisayarın her geçen gün daha fazla eve girmesi, özellikle basit müzik programlarının fiyatlarının ucuzlaması ve programlara daha kolay erişebilme imkanı her geçen gün daha fazla kişiye bir şekilde dijital müzik yapma firsatı sağlamaktadır (Yürür, 2008). 
Bilgisayarın günlük hayatta yaygın kullanım alanları bulması sağlıklı bir toplumsal gelişmenin sağlanması için yeni teknolojik imkan ile farklı bilimsel çalışmaları da gerekli kılmaktadır (Levent, 1994). Teknoloji büyük bir hızla ilerlerken müzikle uğraşan insanların hele ki Konservatuvar veya Müzik Bilimlerinde okuyan öğrencilerin buna kayıtsız kalması veya bundan mahrum kalması çok büyük bir eksiklik olacaktır (Aktükün, 2003). Bu amaçla, araştırma ve geliştirme projeleri, teknoloji uygulamaları ve alan çalışmaları, müzik eğitimini daha yukarılara taşıyacak ve iletişim çağında sesini daha geniş kitlelere ulaştırmada önemli bir rol üstlenecektir (Arapgirlioğlu, 2003).

Finale Nota Yazım Programı ve Otomatik Armonizasyon Özellikleri

Finale geliştirilmiş bir takım müzik notasyon programlarının en iyisidir ve Make Music tarafından Microsoft Windows ve macOS yönetim sistemleri için 1988 yılında piyasaya sunulmuştur (Nicholl ve Grudzinski, 2007). Finale, besteciler tarafından kullanılan yazılım programlarının bir numarasıdır (Purse, 2005). Programın içerisinde nota değerlerinden nüanslara kadar nota yazımında gerekli olabilecek her şey bulunmaktadır (Yengin, 2014). Finale Nota Yazım Programı üzerinde otomatik bir armonizasyon çalışması gerçekleştirmek mümkündür. $\mathrm{Bu}$ çalışmalar, armonizasyon açısından çok olumlu sonuçlar vermese bile en azından öğrencilere eşlikleme ve çokseslendirme alanında farklı fikirler sunabilecek niteliktedir. Programın en belirgin özelliği, armonizasyon işleminin program içerisinde yer alan tüm enstrümanlar üzerinde gerçekleştirilebiliyor olmasıdır. Proje içerisinde koral düzende seçilmiş dört partili bir otomatik armonizasyon çalışması ile orkestrasyon düzende ayarlanan dört partili bir çalışmanın sonuçları aynıdır. Otomatik armonizasyon işlemi en fazla altı parti üzerinde yapılabilmektedir. 


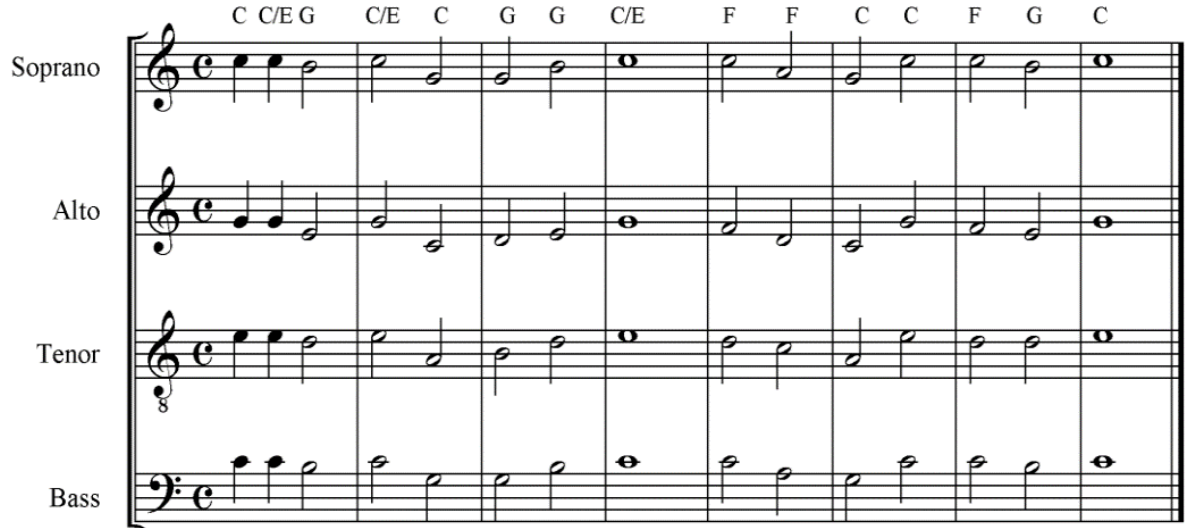

Şekil 1. Finale 2014 nota yazım programı ile koral düzende armonizasyon işlemi

Şekil 1'de görülen çalışma içerisinde araştırmanın deneysel işlem sürecinde yer alan soprano partisi kullanılmıştır. Bu çalışma göstermiştir ki Finale Nota Yazım Programı kullanıcılara farklı bir otomatik armonizasyon işlemi sunmaktadır. 2007 sonrasındaki tüm Finale Nota Yazım Programları ile bu işlem gerçekleştirilebilmektedir. Plug-ins dosyası içerisinde yer alan scoring and arranging ve band-inabox auto-harmonizing sıralı işlem basamakları, bir ezginin orkestrasyon veya koral düzende çokseslendirilmesini sağlamaktadır. Yukarıda belirtildiği gibi proje içerisinde en fazla altı partitür kullanılabilmektedir. Band-in-abox auto-harmonizing içerisindeki tüm armonizasyon işlemleri enstrümanlar değişse bile aynı sonuçları vermektedir. Armonizasyon çalışmaları hem orkestrasyon hem de tek parti içerisinde akor halinde yapılabilir. Bu programda göze çarpan en olumsuz özellik, tam olarak yapılamayan akor çözümlemesidir. Bu durum karşısında kullanıcı, armonizasyon işlemine alacağı ezginin akor çözümlemesini "chord toll" dosyasından manuel olarak yapmak zorundadır.

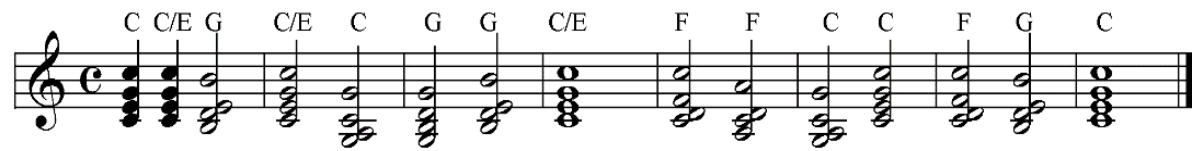

Şekil 3. Finale 2014 nota yazım programı ile dar düzende "six part" "selected staff" (all voices) armonizasyon işlemi 
Şekil 3'de soprano partisinin 6 partide armonilendirilmiş hali akor düzeninde gösterilmiştir. Bu otomatik armonizasyon işlemi, akorların alt bölgesinde bulunan birinci, ikinci ve üçüncü seslerin aynı şekilde dördüncü, beşinci ve altıncı seslere katlanmasıyla oluşmuştur. Birinci ve dördüncü ölçülerde görülen $\mathrm{C} / \mathrm{E}$ (do majör basta mi) akorlarında bas sese "mi" sesi gelmesi gerekirken program yanlış olarak "do" sesini konumlandırmıştır. Akor çözümlemesi araştırmacı tarafından "chord toll" dosyası üzerinden yapılmıştır.

\section{likleri \\ Tonica Fugata Programı ve Otomatik Armonizasyon Özel-}

Tonica Fugata Programında armonizasyon işlemleri altı farklı stilde yapılmaktadır. Bu stiller; 1. Johan Sebastian Bach I, 2. Johan Sebastian Bach II, 3. Max Reger, 4. Samuel Scheidt, 5. Teststil, 6. Jazzstil olarak sıralanmaktadır. Bir ölçüden oluşan bir ezgi örneğinin bu farklı stillerdeki otomatik armonizasyon sonuçları aşağıdaki gibidir.

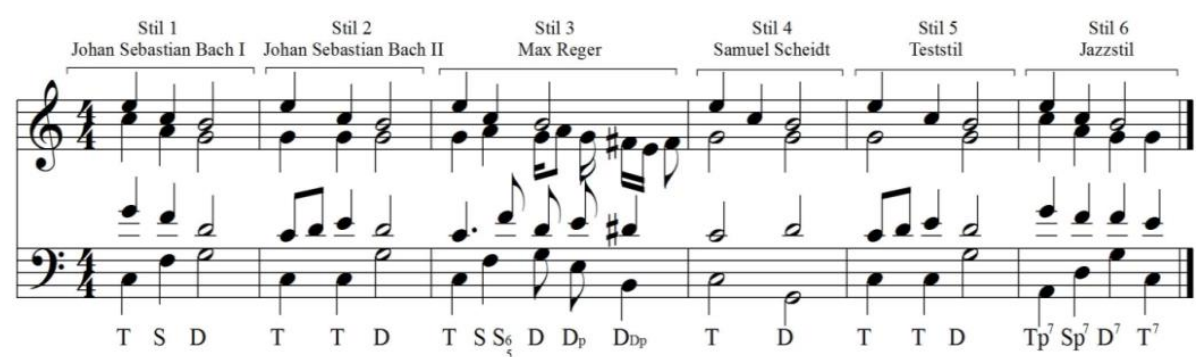

Şekil 4. Tonica Fugata programında farklı stillerde armonizasyon işlemleri

Şekil 4'de görülen otomatik armonizasyon işlemleri için birkaç varyasyon bulunmaktadır. Ezgi yazıldıktan sonra "Compose complete piece" butonuna her tıklandığında farklı bir armonizasyon işlemi elde edilir. Her işlemin akor sembolleri de elde edilen armonizasyon sonucuna bağlı olarak farklıdır. 
Tonica Fugata Programinda Uygulanan Örnek Otomatik Armonizasyon İşlemi

Araștırmacı tarafından yazılan armonizasyon çalıșmasına (Bkz. Şekil 6) ait soprano partisinin Tonica Fugata Programında ki otomatik armonizasyon işlemi şekil 5'de görülmektedir.
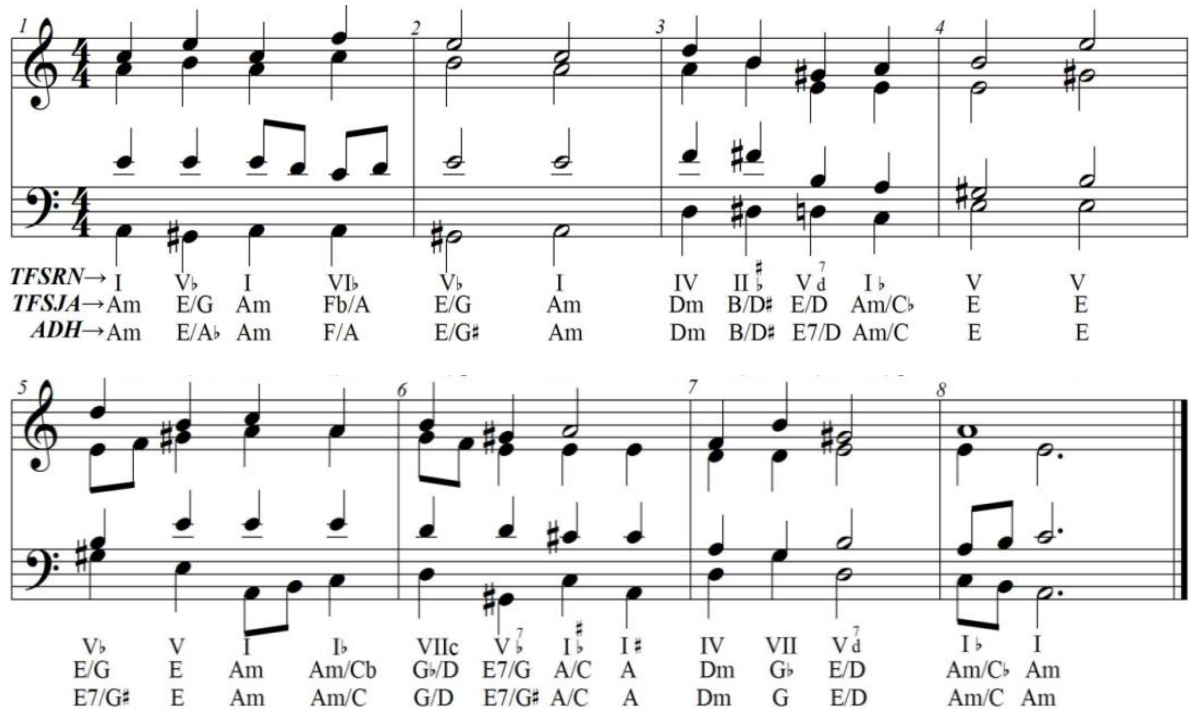

Şekil 5. Jazz still soprano partisi armonizasyon işlemi

Şekil 5'de görülen akorlara ait kısaltmaların açıklamaları şu şekildedir; TFSRN (Tonica Fugata Show: Roman numeral), TFSJA (Tonica Fugata Show: Jazz) ve $A D H$ (Akorların düzeltilmiş hali). TFSRN ve TFSJA Tonica Fugata Programı tarafindan otomatik olarak belirlenen akor sembolleridir. $A D H$ ise akorların düzeltilmiş hali anlamına gelmektedir. Üç akor grubu incelendiği zaman programdan kaynaklanan yanlış akor sembolleri hemen göze çarpmaktadır. Özellikle ana akorların çevrilmiş halleri ile bas partisinde konumlanan sesler (Cb,G,Gb) yanlıș sembolize edilmiștir. Bu durum yedili akorların 1-3-5 akoru olarak yanlış sembolize edilişlerinde (E/DE7/D) ve akorların bas sesler harici diğer seslerinin de yanlış olarak yazılmasında (Fb/A-F/A) görülmektedir. Tonica Fugata Programında yapılan armonizasyon işlemlerinde özellikle bas seslerde oluşturulan küçük altereler görülmektedir. 
Şekil 5'de görülen armonizasyon çalışması incelendiği zaman geleneksel armoni ilkelerine bağlı olarak yapılan analizler şu sonuçları ortaya koymuştur; 4. ölçü, akorların durum değiştirmesi konusuna bağlı olarak doğru armonize edilmiştir. Jazz stili ile yapılan armonizasyon işleminde partiler arası ses sınırının geleneksel klasik armoni kuralları ile örtüştüğü görülmektedir. Bu kurallara bağlı olarak temel durumdaki akorlarda ses katlamaları doğru yapılmıştır.

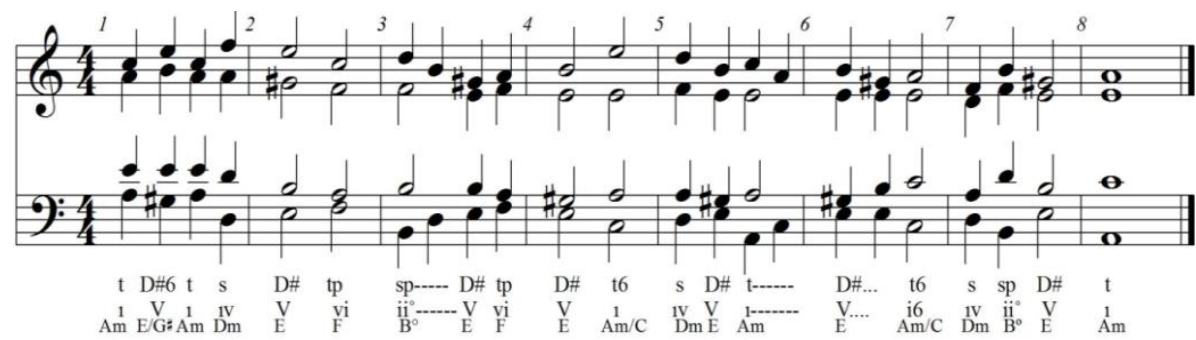

Şekil 6. Soprano partisi armonizasyon işlemi

Şekil 6'da görülen armonizasyon işlemi araştırmacılar tarafından koro düzeninde ve geleneksel armoni ilkeleri doğrultusunda hazırlanmıştır. Akor sembolleri fonksiyonel, basamaksal ve modern armoni sisteminde kullanılan harfler ile gösterilmiştir. $\mathrm{Bu}$ aramonizasyon çalışmasında yer alan soprano partisi, Şekil 5'de ki soprano partisi ile aynidir.

\section{Sibelius Nota Yazım Programı ve Otomatik Armonizasyon Özellikleri}

Finale ile birlikte Sibelius'da, müzik notasyonu için yaygın olarak kullanılan ticari, kapalı kaynak uygulamalardan biridir. $\mathrm{Ne}$ yazık ki Sibelius kromatik-porte notasyonlarında kullanmak için yeterince iyi değildir (Dalley ve Diğerleri, 2009). Sibelius, finale programına göre daha pratik ve doğru çokseslendirme sonuçları veren bir otomatik armonizasyon işlemi sunmaktadır. Note Imput seçildikten sonra Plug-ins dosyası içerisinde yer alan add simple harmony, chord style (block chords, 8 th note (quaver) arpeggios...), label chords with (nothing, chord symbols, romen numerals), melody is in voice $(1,2,3,4)$, change chord (each bar, each beat, each beat group) sirali işlem basamakları, bir ezginin write harmony for (piyano veya gitar) 
için çokseslendirilmesini sağlamaktadır. Finale nota yazım programı ile karşılaştırıldığı zaman bu programda göze çarpan en ayrıcalıklı özellik akor çözümlemesinin otomatik olarak yapılmasıdır. Fakat otomatik olarak atanan akorların doğruluğu kullanıcılar tarafindan mutlaka gözden geçirilmelidir. Çünkü programın otomatik akor atamalarında az sayıda bile olsa belirli hatalar tespit edilmiştir.

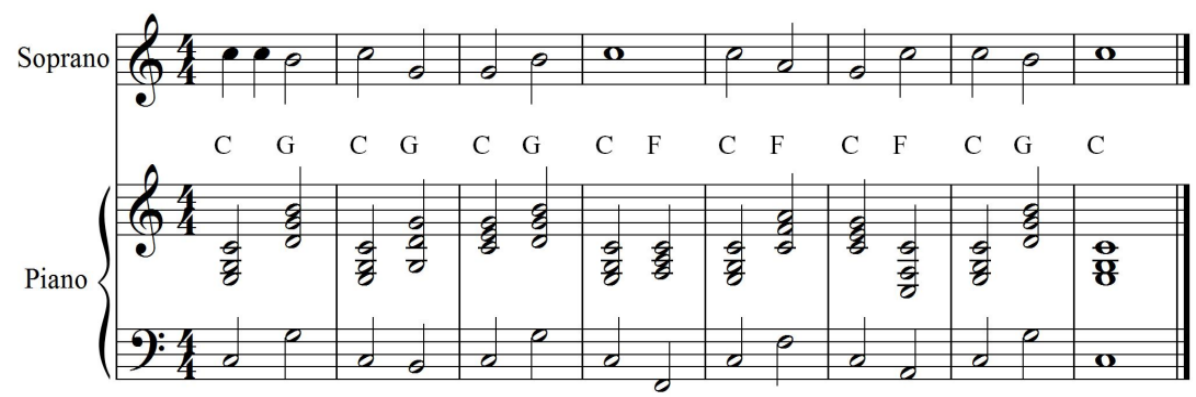

Şekil 7. Chord style block chords soprano partisi armonizasyon işlemi

Şekil 7'de görülen çalışma yukarıdaki açıklamalara örnek olarak gösterilmiştir ve akor yapılarının tekrar gözden geçirilmesi gerekmektedir.
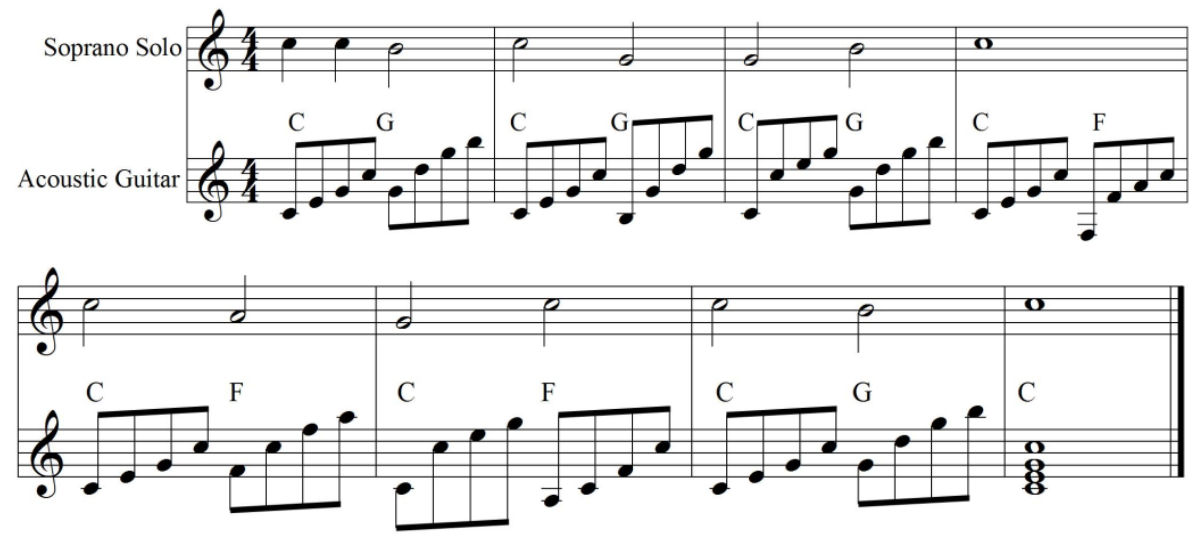

Şekil 8. Chord style 8th note (quaver) arpeggios soprano partisi armonizasyon işlemi 
Şekil 8'de sekizlik notalardan oluşan bir arpej çalışması görülmektedir. Dört farklı arpej seçeneği ile yapılabilen armonizasyon işlemleri Sibelius programını diğer yazılımlardan ayıran en belirgin özelliklerdir.

\section{Yöntem}

\section{Araştırmanın Modeli}

Araştırma betimsel bir çalışma olup üç farklı müzik yazılım programı içerisinde yer alan otomatik armonizasyon işlem özelliklerinin incelenmesi ve bu işlem dosyalarından elde edilen armonizasyon çalışmalarının analiz edilmesi yoluyla tasarlanmıştır. Tonica Fugata programından elde edilen armonizasyon işlemlerinin dereceli puanlama anahtarı yardımıyla üç farklı uzman tarafından puanlanması ise araştırmanın diğer bir boyutudur. Betimsel çalışma; çok sayıda elemandan oluşan bir evrende, evren hakkında genel bir yargıya varmak amacı ile evrenin tümü ya da ondan alınacak bir grup üzerinde yapılan tarama düzenlemeleridir (Karasar, 1986). Popham (1997)'a göre dereceli puanlama anahtarlarından hangisinin kullanılacağı değerlendirmenin amacına bağlıdır. Değerlendirme ölçütlerinin, öğretime ya da değerlendirmeye konu olan performansin ya da ürüne özgü özelliklerin ve boyutların tanımlanmaları gerekir (Tierney ve Simon, 2004).

\section{Veri Toplama Araçları}

Araştırmanın verileri literatür taraması ve armonizasyon analiz çalışması sonuçlarının değerlendirilmesi ile elde edilmiştir. Bu sürecin ilk aşamasında ulusal-uluslararası kaynaklar taranmış ve internet ortamında araştırmalar yapılmıştır. İkinci aşamada ise veri toplama aracı olarak araştırmacı tarafından oluşturulan dereceli puanlama anahtarı kullanılmıştır. Dereceli puanlama anahtarının kapsam geçerliğini belirlemek için 10 maddelik uzman görüş alma formu oluşturularak müzik eğitimi alanında uzman iki akademisyenin görüşlerine başvurulmuştur. Uzman görüşleri doğrultusunda dereceli puanlama anahtarında herhangi bir değişikliğe gidilmemiştir. 
Dereceli puanlama anahtarı içerisinde yer alan davranışlar ve açıklamaları şu şekildedir; 1- Paralel ve düz hareket kısıtlamalarını doğru uygulayabilme. 2- Birinci cümle sonu ve ikinci cümle baş1 akorlarını doğru belirleyebilme. 3- Sesler arası yakın hareketleri doğru oluşturabilme 4- Her ölçüye farklı bir akor ile doğru başlayabilme. 5Partiler arasında ters hareketleri doğru sağlayabilme. 6- Partiler arası ses sınırlarını doğru uygulayabilme. 7- Bitiş akoruna dominant akoru ile doğru bağlantı yapabilme. 8- Akorların ses katlamalarını doğru yapabilme. 9- Akor bağlantılarını genel olarak doğru yapabilme. 10Çevrim akorlarını doğru konumlandırabilme.

Dereceli puanlama anahtarından elde edilen nicel verilerin güvenirliğini belirlemek için puanlayıcılar arası güvenirlik incelenmiştir. $\mathrm{Bu}$ amaçla puanlayıcılar arasındaki uyuşma yüzdesi hesaplanmıştır. Buna göre puanlayıcılar arasındaki uyuşma yüzdesi \% 93,3`ür. Bu sonuca göre puanlayıcılardan elde edilen verilerin güvenilir olduğu sonucuna ulaşılmıştır. Şencan (2005)'a göre puanlayıcılar arası değerlendirme sonuçlarının güvenilir sayılabilmesi için uyuşma yüzdesinin $\% 75$ 'in üzerinde olması gerekmektedir. Bu ölçütün altında bir oran, puanlayıcıların puanlamalarının farklılaştığı şeklinde yorumlanır. Daha düşük bir oran, değerlendirmede, puanlayıcıların önemli ölçüde farklı düşündükleri anlamına gelir.

\section{Verilerin Analizi}

Dereceli puanlama anahtarı üç uzman tarafından puanlanmıştır. Uzmanlardan elde edilen puanların aritmetik ortalaması alınarak dereceli puanlama anahtarında yer alan her bir ölçüt için ayrı ayrı ve toplam puan olarak tabloda gösterilmiştir.

\section{Uygulama}

Armoni analizleri ve puanlama: Araştırmanın bu sürecinde bir soprano partisi çokseslendirme çalışması ve bu çalışmaya ait soprano partisinin Tonica Fugata programındaki otomatik armonizasyon işlemlerine yer verilmiştir. Tonica Fugata programının sunmuş olduğu fark11 armonizasyon özelliklerinden dolayı soprano partisi dört farklı stilde işleme alınmıştır. Çalışmaların her ölçüsü geleneksel armoni kurallarına göre analiz edilmiş ve elde edilen sonuçlar tüm yönleri açıklan- 
mıştır. Tonica Fugata programında akorlar fonksiyonel (function theory), basamak (roman numeral) ve jazz seçenekleri ile sembolize edilmektedir. Armonizasyon işlemlerinde fonksiyonel (function theory) seçeneği tercih edilmiştir. Araştırmacı tarafından deneysel işlem aşaması için koro düzeninde hazırlanan soprano partisi çokseslendirme örneği (Şekil 4) sade bir dokuya sahiptir. Sekizli durumda ve geniş serimde armonilendirilen bu çalışma, otomatik armonizasyon özellikli programlarla elde edilen işlemlere ait negatif analizlerin çözüm önerilerini de göstermektedir.

Araştırmanın bu sürecinde Tonica Fugata programında yer alan J. Sebastian Bach I, J. Sebastian Bach II, Samuel Scheidt ve Teststil stilleri dereceli puanlama anahtarı üzerinde değerlendirilmiştir. Yapılan değerlendirmedeki temel amaç geleneksel klasik armoni ilkeleri ile örtüşen en yüksek puanlı armonizasyon stilini belirlemektir. Değerlendirme yapılırken belirli teknik unsurlara dikkat edilmiştir. Özellikle yakın hareketler ile ters hareketler değerlendirilirken, paralel ve düz hareket kısıtlamaları ile ilgili hataların yapıldığı ölçülere puan verilmemiştir. Örneğin; bir ölçü içerisinde bir paralel hata yapılmışsa doğru olarak yapılan yakın veya ters hareketlere puan verilmemiştir. Her davranış tüm ölçüler ele alınarak değerlendirilmemiştir. Örneğin; 2. (birinci cümle sonu ve ikinci cümle başı akorlarını doğru çözümleyebilme), 7. (bitiş akoruna dominant akoru ile doğru bağlantı yapabilme) ve 10. (çevrim akorlarını doğru konumlandırabilme) davranışlar, ilgili oldukları ölçüler üzerinden değerlendirilmiştir.

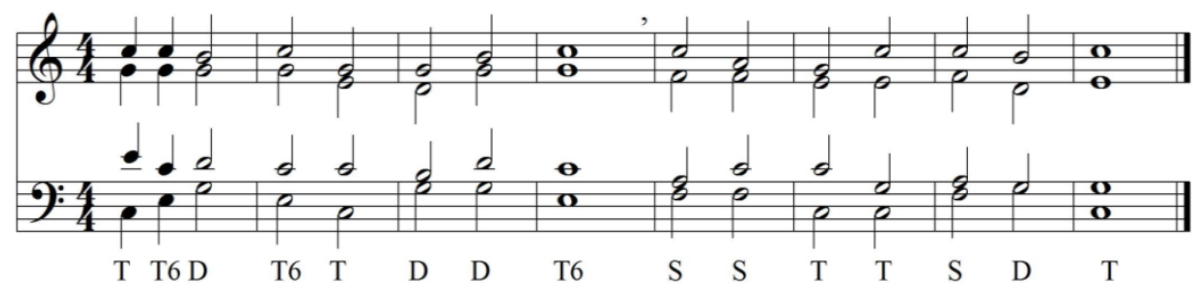

Şekil 9. Araştırmacı tarafından hazırlanan armonizasyon işlemi

Armonizasyonların birinci cümlesinin dar pozisyonla başlaması, iki cümlenin geniş pozisyonda devam ettirilmesi de müzikalite açısından daha uygun olmaktadır (Elhankızı, 2012). Dar serim, iki akor sesinin arasına akorda bulunan diğer ses giremiyor ise dar serim meydana gelir. Ancak bas partisi ile tanor partisi arasına bakılmaz (Acim ve 
Sağer, 2014). Armonizasyon işleminin birinci cümle sonu (4. ölçü sonu) T6 akoru ile sonlandırılmış ve diğer ölçüye sudominant akoru ile geçilmiştir. Cangal (2005)'a göre bir ezginin armonilenmesinde birinci cümle sonunda bazen tonik akora gelindiğinde, devamı sağlamak ve bitiş etkisini (tam kararı) sona bırakmak için tonik akorunun 5'li ya da 3'lü durumunun kullanılması gerekmektedir. Şekil 4'de görülen armonizasyon işlemi bu ilkeler doğrultusunda hazırlanmıştır.

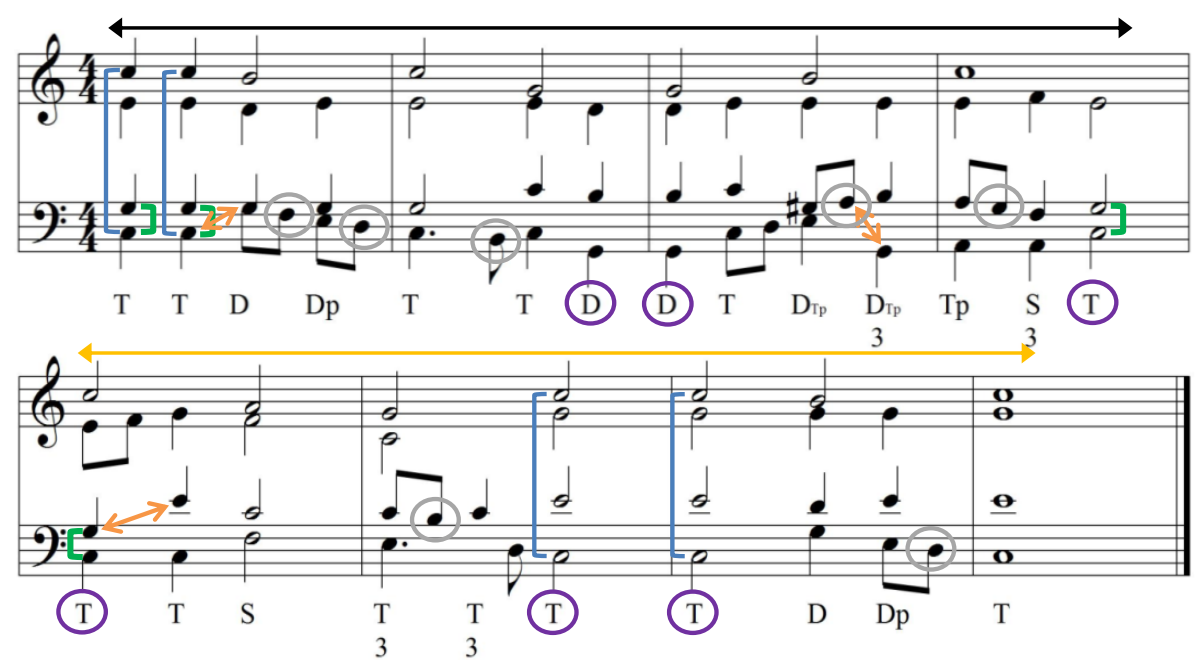

Şekil 10. J. Sebastian Bach I stilinde armonizasyon işlemi

Açıklamalar: Şekil 10 ve diğer çalışmalarda görülen soru (Siyah) ve cevap (Sarı) cümlelerinin sonlarında yer alan bitiş akorlarının müzik formu ilkeleri açısından değerlendirilmesi önemli bir analizdir. Elhankızı (2012)'na göre periyodun yarım ve tam kadansları birbirinden fonksiyonel bitiş akorlarına göre ayrılmaktadır.

Pozitif analizler: Akor bağlanışlarında partilerin olabildiğince yakın hareket yapması yeğlendiğine göre (Cangal, 2005), şekil 5'de alto ve tenor partilerinin tüm ölçülerde birbirine yakın hareketlerle armonilendirildiği görülmektedir. Alto ve soprano partileri arasında oluşturulan koşut 6'lı ve koşut 3'lü aralıklar armoniye duyum açısından farklı bir renk kazandırmıştır.

Negatif analizler: Ölçü başlarında daima yeni akor getirmelidir (Cangal, 2005). Yeni ölçüye mümkün olduğu kadar yeni akor ya da 
aynı akorun farklı konumu ile başlanmalıdır (Acim ve Sağer, 2014). 2. ölçü sonu ve 3. ölçü başında dominant akoru kullanılmıştır (Mor). Aynı durum 4-5 ve 6-7 ölçü bağlantılarında da görülmektedir (Mor). Ayrıca, iki dış parti olan bas ve soprano partilerinde ters hareket sağlanmamıştır. 1-4 ve 5. ölçülerde bas-tenor partileri arasında paralel beşli hatası yapılmıştır (Yeşil).
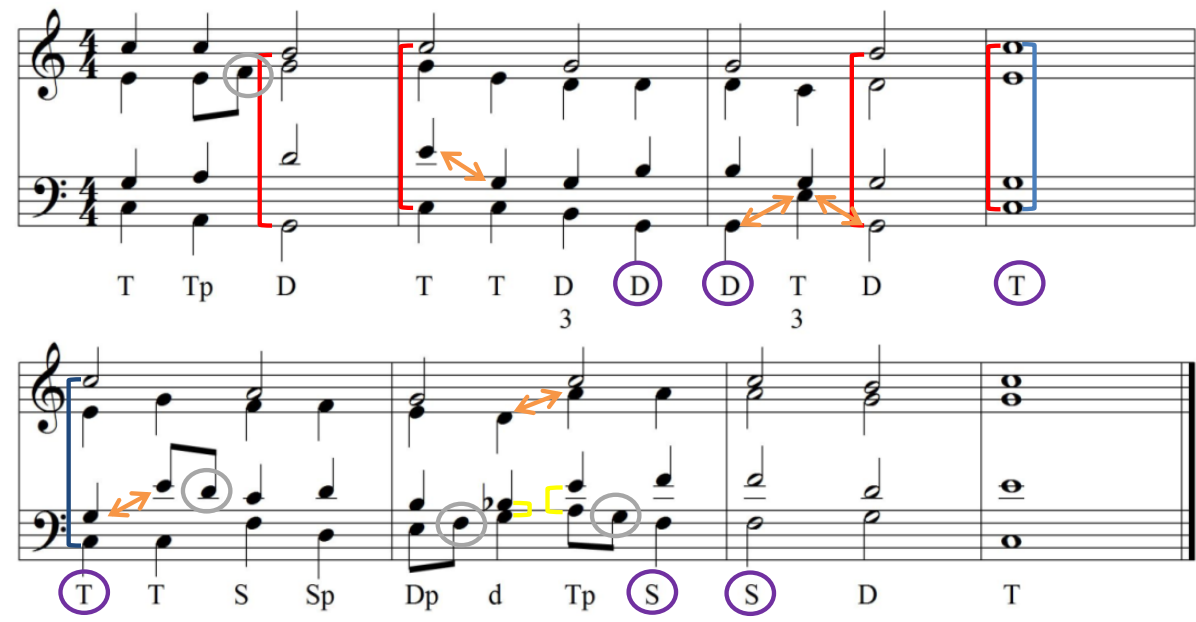

Şekil 11. J. Sebastian Bach II stilinde armonizasyon işlemi

Açıklamalar: Şekil 11'de 3. ve 4. ölçülerde görülen T3 ve D3 akorları birinci çevrim akoru anlamına gelmektedir. Diğer önemli bir ayrınt1, notasyon üzerinde renkli işaretlerin kullanılması ve bu renklerin yapılan analizlerde parantez içerisinde (Kırmızı-sarı-maviyeşil-turuncu-gri) gösterilmesidir. Ayrıca, 6. ölçüde küçük "d" harfi ile sembolize edilen dominant akoru, si bemol değiştirici işareti ile minör akor (sol minör) olduğunu göstermektedir. 5. ve 6. ölçülerde akora yabancı seslerin kullanıldığı görülmektedir. Bu sesler, önceleme (Antisipasyon) olarak analiz edilir (Gri). Bir akorun bir veya daha fazla sesinin bir önceki akorla birlikte duyulması şeklinde tanımlanır. Genellikle süresi kısadır, vuruşun son yarısında veya çeyreğinde yer alır (Çelebioğlu, 2013).

Pozitif analizler: Akorların ses katlamaları doğru yapılmıştır ve tenor-bas partilerinde yoğun olarak ters hareket sağlanmıştır. Alto- 
soprano ve tenor-soprano partileri arasında oluşturulan koşut 6'lı ve koşut 3'lü aralıklar armoniye duyum açısından farklı bir renk kazandırmıştır. Birbirleriyle kaynaşan ama tek ses gibi tınlamayıp dolgun tınlayan bu aralıklar (3'lü ve 6'lılar) iki seslilik çalışmalarında en çok kullanılan aralıklardır (Sağer ve Albuz, 2008). Alto-soprano ve tenorsoprano partileri arasında 8'li aralığı geçen yanlış bir hareket yapılmamıştır. Bitiş akoru, dominant akorundan geçiş yapılarak kurgulanmıştır. Cangal (2005)'a göre tonalitenin I. basamağındaki durucu seslerinden çıkıp V. basamağın yürüyücü seslerine gidiş; bir sona eriş, bir karara varış gereksinimi doğurur ve böylece dominantın gergin durumundan sonra tonik akoruna bağlanarak karara varılmış olunur.

Negatif analizler: 1. ölçüde görülen Tp ve D akor bağlantısı geleneksel klasik armonide genellikle kullanılmaz. Bu ölçüde akorların durum değiştirmesi konusu uygulanabilir veya sudominant akoru kullanılabilirdi. Bu bağlantıya karşıt olarak 6. ölçüde tercih edilen Tp$\mathrm{S}$ akor bağlantısı farklı ve daha olumlu bir etki oluşturmuştur. Bu analizlerin yanı sıra çalışma içerisinde tespit edilen ve geleneksel klasik armoni kuralları içerisinde "sakıncalı" olarak kabul edilen hareketler şu şekilde sıralanmıştır.

1. ölçü sonu dominant (D) akoru ve 2. ölçü başı tonik (T) akorunun bas ve soprano partileri arasında gerçekleşen düz hareket içerisinde gizli sekizli hatası oluşmuştur (Kırmızı).

4. ölçü sonu dominant (D) akoru ve 5. ölçü başı tonik (T) akorunun bas ve soprano partileri arasında gerçekleşen düz hareket sonucu gizli sekizli hatası oluşmuştur (Kırmızı).

4. ölçü tonik (T) akoru ve 5. ölçü başı tonik (T) akorunun bas ve soprano partileri arasında paralel sekizli hatası oluşmuştur (Mavi).

6. ölçü üçlü dominant (d) akorundan çıkıcı olarak beşlik tonik paraleli (Tp) akoruna bas ve tenor partileri arasında düz hareket yapılmıştır (Sarı). Beşliden küçük bir aralıkla çıkıcı olarak 5'liye gitmek çoğu kez iyi değildir (Cangal, 2005).

Birinci cümle sonu (4.ölçü) tonik akorla bitmiştir ve diğer ölçüye (5.ölçü) tekrar tonik akoru ile devam edilmiştir. Ayrıca bazı partilerde gereksiz uzak hareketler yapılmıştır (Turuncu). 

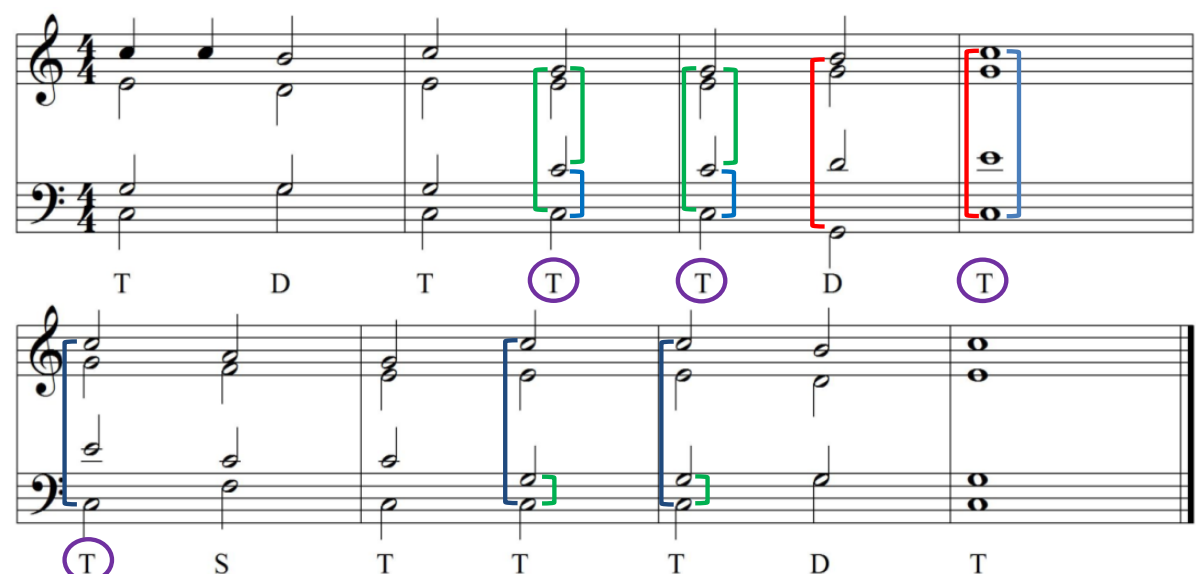

Şekil 12. Samuel Scheidt stilinde armonizasyon işlemi
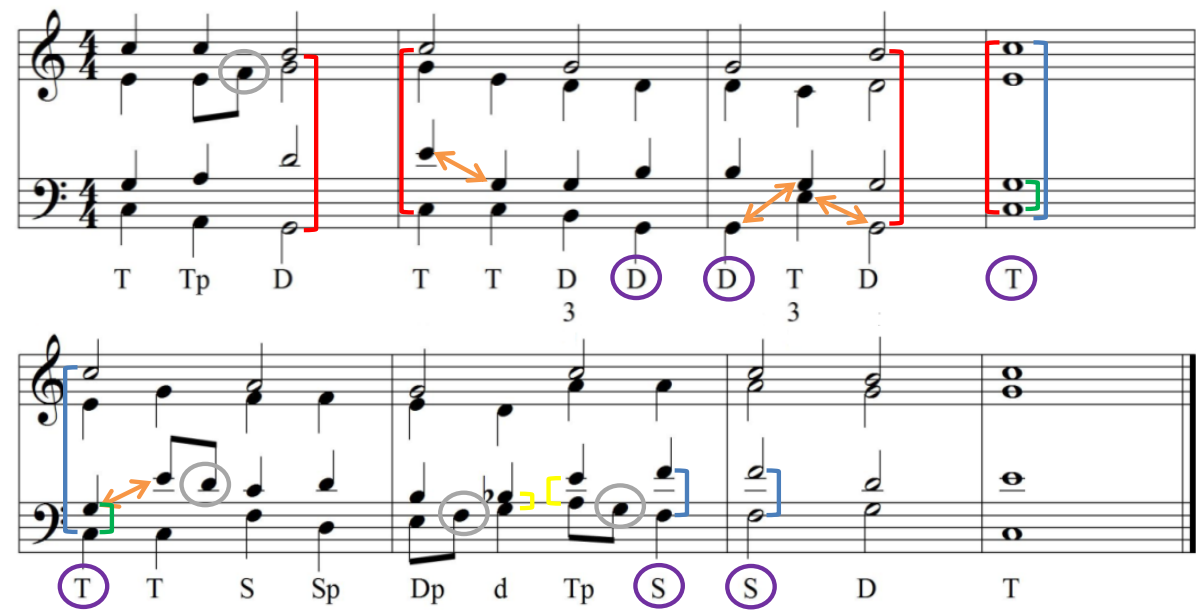

Şekil 13. Teststil stilinde armonizasyon işlemi

\section{Bulgular}

J. Sebastian Bach I, J. Sebastian Bach II, Samuel Scheidt ve Teststil stillerinde armonizasyon işlemine ilişkin puan ortalamaları Tablo 1`de gösterilmiştir. 
Tablo 1. J. Sebastian Bach I, J. Sebastian Bach II, Samuel Scheidt ve Teststil stillerinde armonizasyon işlemine ilişkin puan değerleri

\begin{tabular}{lcccc}
\hline Ölçütler & $\begin{array}{c}\text { J. } \\
\text { Sebastian } \\
\text { Bach I }\end{array}$ & $\begin{array}{c}\text { J. Sebas- } \\
\text { tian Bach } \\
\text { II }\end{array}$ & $\begin{array}{c}\text { Samuel } \\
\text { Scheidt }\end{array}$ & Teststil \\
\hline $\begin{array}{l}\text { Paralel ve düz hareket kısıtlama- } \\
\text { larını doğru uygulayabilme }\end{array}$ & 2 & 2 & 1 & 1 \\
\hline $\begin{array}{l}\text { Birinci cümle sonu ve ikinci } \\
\text { cümle başı akorlarını doğru } \\
\text { çözümleme }\end{array}$ & 0 & 0 & 0 & 0 \\
\hline $\begin{array}{l}\text { Sesler arası yakın hareketleri } \\
\text { doğru oluşturabilme }\end{array}$ & 2 & 3 & 1.67 & 1 \\
\hline $\begin{array}{l}\text { Her ölçüye farklı bir akor ile } \\
\text { doğru başlayabilme }\end{array}$ & 3 & 3 & 3 & 3 \\
\hline $\begin{array}{l}\text { Partiler arasında ters hareketi } \\
\text { doğru sağlayabilme }\end{array}$ & 1 & 1 & 1 & 1 \\
\hline $\begin{array}{l}\text { Partiler arası ses sınırını doğru } \\
\text { uygulayabilme }\end{array}$ & 4 & 4 & 4 & 4 \\
\hline $\begin{array}{l}\text { Bitiş akoruna dominant akoru } \\
\text { ile bağlantı yapabilme }\end{array}$ & 3.33 & 4 & 4 & 4 \\
\hline $\begin{array}{l}\text { Akorların ses katlamalarını } \\
\text { doğru yapabilme }\end{array}$ & 4 & 4 & 4 & 4 \\
\hline $\begin{array}{l}\text { Akor bağlantılarını genel olarak } \\
\text { doğru yapabilme }\end{array}$ & 3 & 3 & 3 & 4 \\
\hline $\begin{array}{l}\text { Çevrim akorlarını doğru ko- } \\
\text { numlandırabilme }\end{array}$ & 0 & 2 & 0 & 2,33 \\
\hline \begin{tabular}{l} 
Toplam \\
\hline
\end{tabular} & $\mathbf{2 2 . 3 3}$ & $\mathbf{2 6}$ & & $\mathbf{2 4 3 3}$ \\
\hline
\end{tabular}

Tablo 1'e göre en yüksek puana sahip stillerin sirasiyla J. Sebastian Bach II, Teststil, J. Sebastian Bach I ve Samuel Scheidt stili olduğu görülmektedir. Bu sonuçlar, programın geleneksel armoni ilkeleri ile en çok örtüşen armonizasyon stilinin J. Sebastian Bach II; en az örtüşen stilin ise Samuel Scheidt olduğunu göstermektedir. Tüm stillerde partiler arası ses sinırı ve akorların ses katlamaları kurallarına uyularak bitiş akoru bağlantıları doğru yapılmıştır. Bitiş akorunun uygulanmasında J. Sebastian Bach I stilinde Dp akorunun kullanılmasından kaynaklanan düşük bir puana (3.33) rastlanmıştır. Yine tüm stillerde birinci cümle sonu ve ikinci cümle başındaki akorların doğru çözümlenmediği görülmektedir. 


\section{Sonuç, Tartışma ve Öneriler}

Yapılan analizler, Finale Nota Yazım Programında yer alan armonizasyon işlemlerinin tamamen orkestrasyon düzenleme içerikli bir özelliğe sahip olduğunu göstermektedir. Bu program ile geleneksel klasik armoni ilkeleri doğrultusunda koral düzenli bir çalışma yapmanın mümkün olmadığ 1 görülmektedir. Ayrıca, Tonica Fugata programında yapılan armonizasyon işlemlerine ait periyotlarda müzik formu ilkeleri açısından belirli eksiklikler görülmüştür. Özellikle soru ve cevap cümlelerinde konumlandırılan bitiş akorları birbirleri arasında ayırt edici bir yapıya sahip değildirler ve duyum açısından da tekdüzelik oluşturmuşlardır. Sibelius programı ise piyano ve gitar için tasarlanmış bir otomatik armonizasyon işlem özelliğine sahiptir.

Tonica Fugata Programı, Finale ve Sibelius programlarına göre öğrenciler ve eğitimciler tarafından daha az tercih edilmektedir. Sevinç ve Koldemir (2009) araştırmalarında "Bilişim Destekli Müzik" derslerinde en çok kullanılan ve tercih edildiği düşünülen programların, "Finale, Sibellius, Cubase, Sound Forge ve Wave Lab" oldukları sonucuna ulaşmışlardır. Tonica Fugata Programı, nota yazımı açısından diğer programlar gibi pratik değildir ve içeriği bütünüyle çokseslendirme amaçlı tasarlanmıştır. Program, araştırmanın amacı doğrultusunda değerlendirildiği zaman otomatik armonizasyon işlem özellikleri açısından oldukça kapsamlı özelliklere sahiptir. Programın otomatik armonizasyon içerikli özelliklerinin müzik eğitimi alanına sağlayacağı katkılar araştırıldığı zaman ortaya olumlu sonuçların çıkabileceği yüksek bir olasılıktır.

Tonica Fugata Programından elde edilen olumlu sonuçlar şu şekildedir: 1- Programın dikey armonileme dışında sunmuş olduğu yatay armoni ve kanon özellikli armonizasyon işlemeleri, öğrencilere farklı çalışma stratejileri sunmaktadır. 2- Deneysel işlem bölümünde kullanılan çalışmalar incelendiği zaman bitiş akoru (T) bağlantısı sürekli ve doğru olarak dominant akoru ile yapılmıştır. 3- J. Sebastian Bach I ve II stillerinde kullanılan akora yabancı sesler, yan basamak akorları ve çevrim durumunda olan akorlar, armonizasyon işlemine renkli bir boyut kazandırmıştır. 4- Bas partisinde yer alan bütün sesler doğru şekilde sembolize edilmiştir. 5- Alto-soprano ve tenor-soprano partileri arasında ses aralığı aşımı olmamıştır. 6- Özellikle iki dış parti 
olan soprano-bas partilerinde ve diğer parti ilişkilerinde belirli düzeyde ters hareketler sağlanmıştır. 7- Dominant akorundan sonra sudominant akoru hiç kullanılmamıştır. Programın bu tarz nitelikli yönleri öğrencilere olumlu fikirler verebilmekle birlikte, muhakeme yapmalarını da sağlamaktadır. Bu olumlu sonuçların yanı sıra deneysel işlem sürecinde göze çarpan diğer analizler şu şekildedir: 1- Samuel Scheidt stilinde çevrim veya yan basamak akorları hiç kullanılmamıștır. 2- J. Sebastian Bach I, J. Sebastian Bach II ve Teststil dosyalarında yapılan armonizasyon işlemlerinde yoğun bir şekilde akora yabancı sesler oluşmuştur. Alto, tenor ve bas partilerinde dörtlük nota değerinde oluşan bu yabancı sesler, ayrı bir akor ile armonilendirilmiştir. 3- J. Sebastian Bach ve Teststil dosyalarında kullanılan Sp akoru, sürekli temel halinde kurgulanmıştır. Cangal (2005)'a göre Sp akoru çoğu zaman birinci çevrim (6’l1) durumunda kullanılır; bu durumda bas partisinde kullanılan akorun 3'lüsü sudominantın temel sesi olduğundan, sudominant etkisi daha iyi hissedilir. 4Dominant (D) ve sudominant paraleli (Sp) akorlarının yedili haline hiç rastlanmamıştır. 5- İkinci çevrim akorları hiç kullanılmamıştır.

Öğrencilerin armoni derslerinde Finale, Sibelius ve Tonica Fugata programlarından faydalanabilmeleri adına farklı stratejiler geliştirilebilir. Örneğin, öğrencilerin kendi uğraşları ile gerçekleştirdikleri bir armoni çalışması ve bu çalışmalarını otomatik armonizasyon işlemleri ile karşılaştırmaları önemli bir stratejidir. Araştırmada ele alınan müzik yazılım programları üzerinde farklı armonize işlemleri bulunmaktadır. $\mathrm{Bu}$ programların sunmuş olduğu farklı düzenleme seçenekleri kullanılarak yalın dokulu ezgiler üzerinden orkestrasyon düzenlemeleri kolaylıkla yapılabilir. Bu tarz çalışmalar öğrencilere farklı düzenleme fikirleri sunmakta ve grup çalışma yönlerini de geliştirmektedir. Wilkinson (1997) bu yazılımların müzik öğretmenlerinin kendilerini geliştirmelerine yardımcı olmalarının yanı sıra bu alanda çalışan öğrencilere de bireysel ve grup çalışmalarında, yeni yöntemler ile önemli katkılar sağlayacağını belirtmektedir.

Müzik öğretmeni adayları, mesleki hayatlarında müzik yazılım programlarına hem ders içerisinde hem de farklı müzikal etkinliklerde ihtiyaç duyabilirler. Bilgin (2005)'e göre müzik öğretmeni olacak her öğrenci mutlaka bilgisayarı çok iyi bilmeli, farklı müzik yazılımlarını da bu bilgisiyle bütünleştirmelidir. Sever (2001) müzik teknolojisi 
kullanımı için, elektronik dünyası ve özellikle bilgisayar sistemleri hakkında müzik eğitimcilerinin de bilgilendirilmeleri gerektiği görüşündedir.

Nota yazılım programları üzerinde otomatik armonizasyon işlemleri kullanılarak okul şarkıları için eşlik çalışmaları da yapılabilir. Beşer (2010) nota yazım programlarının yardımıyla bir eser için eşlik oluşturulabileceğini ve bu çalışmalar üzerine farklı midi enstrümanların da eklenebileceğini belirtmektedir. Bu tarz eklentiler, hazırlanacak eşlik projelerine hem armonik bir renk hem de orkestral bir zenginlik kazandırabilir. Teknoloji ve müzik eğitimi alanı ile ilişkilendirilen araştırmalardan elde edilen sonuçlar, müzik yazılım programlarının gerekliliğini ve öğretmen adaylarına sağlayacağ önemli katkıları işaret etmektedir.

\section{Kaynaklar}

Acim, S. \& Sağer, T. (2014). Müzik Öğrencileri İçin Temel Armoni Bilgileri. Ankara: Gece Kitaplığı.

Aktükün, B. (2003). Müzik ve Müzik Eğitimi Alanında Bilgisayar Kullanımı, Cumhuriyetimizin 80. Yllinda Müzik Sempozyumu, 148-150.

Arapgirlioğlu, H. (2003). Türk Okul Şarkılarının Teknoloji Destekli Çokseslendirilmesine Ilişskin Yaklaşımlar, Yayımlanmamış Doktora Tezi, Gazi Üniversitesi, Eğitim Bilimleri Enstitüsü, Ankara.

Arapgirlioğlu, H. (2003). Müzik Teknolojisi ve Yeni Yüzyılda Müzik Eğitimi, Cumhuriyetimizin 80. Yllinda Müzik Sempozyumu, 160-164.

Azizi, A. (2005). Ortaöğretim Kurumlarında Bilgisayar Destekli Müzik Öğretim Yönteminin Öğrencilerin Gelişimleri Üzerindeki Etkisi, Yayımlanmamış Yüksek Lisans Tezi, Marmara Üniversitesi, Eğitim Bilimleri Enstitüsü, İstanbul.

Beşer, U. (2010). Müzik Eğitiminde Teknoloji Kullanımının Müzik Eğitimcileri Açısından Değerlendirilmesi, Yayımlanmamış Yüksek Lisans Tezi, Sakarya Üniversitesi, Sosyal Bilimler Enstitüsü, Sakarya.

Bilgin, B. (2005). Müzik Öğretmeni ve Eğitim Teknolojisi. Ístanbul Müzik Öğretmenleri Seтроzуити,

Cangal, N. (2005). Armoni. Ankara: Arkadaş yayınevi.

Çelebioğlu, E. (2013). Armoni. İstanbul: Pan Yayıncıllk.

Dalley, K. \& Johnston, M. \& Keislar, D. \& Keller, J. \& Morris, P. (2009). The Music Notation Project. Erişim tarihi: 14.10.2016. 
Ali Korkut Uludă̆ / Ë̈ Ĕ̈itim Fakültesi Dergisi, 18-2(2016), 1073-1095

< http://musicnotation.org/software/sibelius/>

Elhankızı, A. (2012). Armoni Klasik Batı Sistemine Rus Ekolu Yaklaşımları. Konya: Eğitim Yayınevi.

Kaptan, S. (1998). Bilimsel Araştırma ve İstatistik Teknikleri. Ankara: Tekışık Web Yayınlar1.

Karasar, N. (1986). Bilimsel Araştırma Yöntemi. Ankara: Bilim Kitapevi.

Koç, A. (2004). Günümüzde Bilgisayar Destekli Müzik Yazılımlarının Müzik Eğitimine Katkıları. 1924-2004 Musiki Muallim Mektebinden Günümüze Müzik Öğretmeni Yetiştirme Sempozyumu,1-6.

Levendoğlu, O. (2004). Teknoloji Destekli Çağdaş Müzik Eğitimi, 1924-2004 Musiki Muallim Mektebinden Günümüze Müzik Öğretmeni Yetiştirme Sempozyumu.

Levent, D. (1994). Bilgisayar Tutum Ölçeği (BTÖ-M)’Nin Geçerlik Güvenirlik, Norm Çalışması Ve Örnek Bir Örnek Uygulama, Yayımlanmamış Doktora Tezi, Marmara Üniversitesi, Sosyal Bilimler Enstitüsü, İstanbul.

Nicholl \& Grudzinski. (2007). Finale (Software). Erişim tarihi: (12.10.2016). $<$ https://en.wikipedia.org/wiki/Finale_(software)>

Wilkinson, S. (1997). Anathomy of a home studio. C.A. EM Boks, Emeryuille.

Popham, J. W. (2000). Modern Educational Measurement. Needham: Allyn \& Bacon.

Purse, B. (2005). Finale (Software). Erişim tarihi: 12.10.2016. $<$ https://en.wikipedia.org/wiki/Finale_(software)>

Sağer ve Albuz. (2008). Ĕ̌gitim Müziği Besteleme Teknikleri. Ankara: Maya Akademi Yayın Dağıtım.

Sever, S. (2001). Elektronik Müzik Teknolojisi Eğitimi ve Önemi, Yayımlanmamış Yüksek Lisans Tezi, Abant İzzet Baysal Üniversitesi, Sosyal Bilimler Enstitüsü, Bolu.

Sevinç, S. ve Koldemir, S. (2009). Anadolu Güzel Sanatlar Liselerinde Bilgisayar Destekli Müzik Eğitiminin Kullanilabilme Durumu. Selçuk ÜniversitesiAhmet Keleşoğlu Eğitim Fakültesi Dergisi. Sayı (21), 287-305.

Sevinç, S. (2003). Teknoloji Desteği İle Çokseslendirilen Okul Şarkılarının İlköğretim İkinci Devre Öğrencilerinin Öğrenme Düzeyine Etkileri. Cumhuriyetimizin 80. Yılında Müzik Sempozyumu, 240-242.

Şencan, H. (2005). Sosyal ve Davranışsal Ölçmelerde Güvenirlik ve Geçerlik. Ankara: Sözkesen Matbaacılık.

Tierney, R. \& Simon, M. (2004). What's still wrong with rubrics : Focusing on the contistency of performance criteria across scale levels. Pratical Assessment, Research and Evaluation, 9 (2).

Wilkinson, S., (1997), Anathomy of a home studio, EM Boks, Emeryuille, C.A 
Ali Korkut Uludă̆ / Ë̈ Ĕgitim Fakültesi Dergisi, 18-2(2016), 1073-1095

Yengin, A. (2014). Müzik Teknolojilerinin Örgün Müzik Eğitiminde Kullanılma Durumlarına İlişkin Öğretmen Görüşleri: Burdur İli Örneği, Yayımlanmamış Yüksek Lisans Tezi, Mehmet Akif Ersoy Üniversitesi, Eğitim Bilimleri Enstitüsü, Burdur.

Yürür, Deniz, M. (2008). Dijital Müzik. İstanbul: Pusula Yayıncılık.

\section{Extended Summary}

\section{Purpose}

It was determined from literature review that quality and quantity of the studies using the note software programs; finale and sibelius to some extent are limited. Tonica Fugata is another software program among those belonging to musical science and related academic literature which seems not to be used densely. When considered all these points, the main point in the study is to investigate thoroughly the automated harmonisation processes included by finale, sibelius and tonica fugata software programs. Secondary aim of the study is to determine the overlapping aspects of automated harmonisation characteristics with traditional classical harmony principles. After the determination of general view of programs through descriptive analyses, numerical results tried to be obtained from different harmonisation styles taking place in tonica fugata programs. Main purpose at this point is to support descriptive analyses with numerical data.

\section{Method}

The study is a descriptive research and designed by investigating automated harmonisation process characteristics of three different music software programs and analysing soprano party polyphonic works obtained from these process files. Another important aspect of the study is the evaluation of harmonisation processes obtained from Tonica Fugata program by three experts through gradual scoring key harmonisation processes. According to Kaptan (1998), scientific events start by describing phenomena and thus understanding them better, providing grouping opportunities and determining the relationship between them.

\section{Results}

The highest score in harmonisation processes conducted for Tonica Fugata software was given to styles J. Sebastian Bach II (26 p), Teststil (24.33 p), J. Sebastian Bach I (22.33 p) and Samuel Scheidt (21.67) styles. Such results show that the harmonisation style overlapping with the the traditional harmony principles of the program the most was determined to be J. Sebastian Bach II while the least overlapping one is that of Samuel Scheidt. In all styles, connections of ending accords were constructed correctly by obeying the rules of voice limits between parties and voice layers of the accords. In the application of the ending accord, a low score (3.33) was seen resulting from the use of Dp accord in J. Sebastian Bach I style. It was seen in 
again all styles that accords were designed correctly at the end of the first sentence and the beginning of the second one.

\section{Discussion}

Tonica Fugata software program is preferred by teachers and learners less than Finale and Sibelius programs. Such a situation results from the fact that it is not as practical as other programs for note writing and its content is designed absolutely for polyphonic aims. It is seen when the program is evaluated in convenience with the aim of the study that it has very comprehensive characteristics for automated harmonisation process properties. It is highly possible that some positive results may be seen when considered the contributions of the automated harmonisation content features of the program to music education field.

\section{Conclusion}

Analyses in the study show that harmonisation processes taking place in Finale note software have a full orchestration design coverage. It is seen that it is not possible using this program to make a coral designed work in convenience with traditional classical harmony principles. In addition, it was found that there are some deficiencies in periods belonging to harmonisation processes carried out in Tonica Fugata program in the respect of the principles in musical forms. Ending accords located in question and answer sentences do not exhibit a distinguishing structure between among themselves and show an audial mono-form.

Positive results obtained from Tonica Fugata software program are as follows. 1- harmonisation processes with cannon and horizontal harmony characteristics the program offers in addition to vertical harmonisation allow students to use different working strategies, 2 - it is seen when the studies used in experimental process section are taken into consideration that $\mathrm{T}$ junction of ending accord is completed using permanently dominant accord, 3 - foreign voices for the accord used in $\mathrm{J}$. Sebastian Bach I and II styles, side stage accords and circuiting accords elaborated harmonisation process, 4- all the voices in Bass party were symbolized correctly, 5no voice interval excess was experienced between Alto-soprano and tenor-soprano parties. 6- reverse motions at certain level in especially the relations between two outer parties; soprano-bas parties and other parties were provided, 7- sub-dominant accord was never used after dominant accord. Such positive aspects of the program can give positive opinions to students and allow them make comparison. In addition to such positive results, other analyses experienced in experimental processes are as follows; 1 - circuiting or side stage accords were never used in Samuel Scheidt style, 2 - voices foreign to accord were seen densely in harmonisation processes experienced in J. Sebastian Bach I, J. Sebastian Bach II and Test style files; these foreign voices forming in quartet note value in alto, tenor and bas parties were harmonised with a different accord. 3- J. Sp accord used in Sebastian Bach and Test style files was set up in continuous footing. According to Cangal (2005), Sp accord is mostly used in the first circuit (sextet); in such a situation, trio of accord used in bass party 
is the basic voice of subdominant and therefore, the effect of subdominant is felt better; 4- septet form of dominant (D) and subdominant parallel (Sp) accords was never experienced, 5- second circuit accords were never used. 